\title{
Flight Test Validation of a Frequency-Based System Identification Method on an F-15 Aircraft
}

Gerard S. Schkolnik

NASA Dryden Flight Research Center

Edwards, California

John S. Orme

NASA Dryden Flight Research Center

Edwards, California

Mark A. Hreha

McDonnell Douglas Aerospace

St. Louis, Missouri 


\title{
FLIGHT TEST VALIDATION OF A FREQUENCY-BASED SYSTEM IDENTIFICATION METHOD ON AN F-15 AIRCRAFT
}

\author{
Gerard S. Schkolnik* and John S. Orme \\ NASA Dryden Flight Research Center \\ Edwards, California \\ Mark A. Hreha** \\ McDonnell Douglas Aerospace \\ St. Louis, Missouri
}

\section{Abstract}

A frequency-based performance identification approach was evaluated using flight data from the NASA F-15 Highly Integrated Digital Electronic Control aircraft. The approach used frequency separation to identify the effectiveness of multiple controls simultaneously as an alternative to independent control identification methods. Fourier transformations converted measured control and response data into frequency domain representations. Performance gradients were formed using multiterm frequency matching of control and response frequency domain models. An objective function was generated using these performance gradients. This function was formally optimized to produce a coordinated control trim set. This algorithm was applied to longitudinal acceleration and evaluated using two control effectors: nozzle throat area and inlet first ramp. Three criteria were investigated to validate the approach: simultaneous gradient identification, gradient frequency dependency, and repeatability. This report describes the flight test results. These data demonstrate that the approach can accurately identify performance gradients during simultaneous control excitation independent of excitation frequency.

\section{Nomenclature}

\section{ACTIVE Advanced Control Technology for Integrated Vehicles}

\footnotetext{
* Aerospace Engineer, Senior Member AlAA

†Aerospace Engineer, Member AIAA

** Aerospace Engineer, Member AIAA

Copyright $(1995$ by the American Institute of Aeronautics and Astronautics, Inc. No copyright is asserted in the United States under Title 17, U.S. Code. The U.S. Government has a royalty-free license to exercise all rights under the copyright claimed herein for Governmental purposes. All other rights are reserved by the copyright owner.
}

\author{
AdAPT \\ Adaptive Aircraft Performance \\ Technology
}

ADECS Advanced Engine Control System

$A J \quad$ nozzle throat area, $\mathrm{ft}^{2}$

$C \quad$ estimated derivative of longitudinal force coefficient with respect to symmetric nozzle throat area during separate control excitation

$C_{x_{\delta}} \quad$ estimated derivative of longitudinal force coefficient with respect to symmetric nozzle throat area during simultaneous control excitation

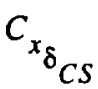

estimated derivative of longitudinal force coefficient with respect to symmetric cowl position during separate control excitation

estimated derivative of longitudinal force coefficient with respect to symmetric cowl position during simultaneous control excitation

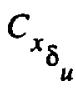

derivative of longitudinal force coefficient with respect to control deflection

fan variable vanes, deg

DEEC Digital Electronic Engine Control

DFTP discrete Fourier transform points

EAIC electronic air inlet controller

EPR engine pressure ratio 


\begin{tabular}{|c|c|}
\hline FFT & fast Fourier transform \\
\hline F.S. & control full-scale range \\
\hline FTIT & fan turbine inlet temperature \\
\hline$g$ & gravitational acceleration, $32.174 \mathrm{ft} / \mathrm{sec}^{2}$ \\
\hline HIDEC & $\begin{array}{l}\text { Highly Integrated Digital Electronic } \\
\text { Control }\end{array}$ \\
\hline $\mathrm{n}$ & frequency bin number of FFT \\
\hline $\mathrm{N} 1 \mathrm{C} 2$ & corrected fan speed, rpm \\
\hline$N_{x}$ & longitudinal acceleration, $g$ \\
\hline$N_{z}$ & normal acceleration, $g$ \\
\hline$P n$ & normalized spectrum \\
\hline PSC & Performance Seeking Control \\
\hline $\bar{q}$ & average dynamic pressure, $1 \mathrm{bf} / \mathrm{ft}^{2}$ \\
\hline$R C V V$ & compressor variable vanes, deg \\
\hline $\mathrm{RHO}$ & inlet first ramp or cowl position, deg \\
\hline$S$ & reference wing area, $608 \mathrm{ft}^{2}$ \\
\hline SNR & signal-to-noise ratio \\
\hline $\operatorname{SNR} N_{x_{A J}}$ & $\begin{array}{l}\text { signal-to-noise ratio of } N_{x} \text { with respect } \\
\text { to nozzle throat area during separate } \\
\text { control excitation }\end{array}$ \\
\hline $\operatorname{SNR} N_{x_{A J^{\prime}}}$ & $\begin{array}{l}\text { signal-to-noise ratio of } N_{x} \text { with respect } \\
\text { to nozzle throat area during } \\
\text { simultaneous control excitation }\end{array}$ \\
\hline $\operatorname{SNR} N_{x} C S$ & $\begin{array}{l}\text { signal-to-noise ratio of } N_{x} \text { with respect } \\
\text { to cowl position during separate } \\
\text { control excitation }\end{array}$ \\
\hline $\operatorname{SNR} N_{x_{C S}}$ & $\begin{array}{l}\text { signal-to-noise ratio of } N_{x} \text { with respect } \\
\text { to cowl position during simultaneous } \\
\text { control excitation }\end{array}$ \\
\hline$S R$ & sample rate, samples/sec \\
\hline $\mathbf{u}$ & control effector \\
\hline$\omega$ & excitation frequency, $\mathrm{Hz}$ \\
\hline
\end{tabular}

$W t$

$\Delta$

$\underline{\text { Subscripts }}$

$c$

i

$n$

\section{Superscripts}

, steady-state trim condition

\section{Introduction}

An onboard optimization algorithm can increase aircraft performance without the additional penalty of weight or modification to control system architecture, resulting in significant cost savings. Performance and reduced life-cycle cost are critical factors in the decision to procure commercial and military aircraft. Small advantages in range, payload, and endurance separate contract winners from the competition. For over 15 years, NASA Dryden Flight Research Center, Edwards, California, has pursued and demonstrated control methodologies for improving aircraft performance in fight. Digital control, the key enabling technology, has provided a means by which previously independent systems, such as the flight and engine control, can share digital data and achieve improved performance.

The Advanced Engine Control System (ADECS) program was the first to use digital data communication between the engine and flight control computers to increase engine performance (ref. 1). The ADECS approach improved performance by trading stall margin for increased thrust or by reducing fuel consumption using fixed control schedules. This system did not contain an adaptive capability, so it was unable to sense the operating condition of the engine and to compensate for levels of degradation. The Inlet Integration program similarly shared digital data among flight, engine, and inlet controls to improve the integrated engine and inlet performance, but it also relied upon predetermined control schedules generated from models.

The Performance Seeking Control (PSC) program followed the ADECS program and was the first to 
incorporate a model-based, real-time adaptive onboard propulsion system optimization algorithm (ref. 2-3). The PSC algorithm's adaptive capability came from a Kalman filter that identified the state of deterioration of the engine components. The Kalman filter updated an integrated system model to represent the current engine state. The optimization process used linear programming techniques to determine the optimal engine operating condition for the selected performance measure. The PSC performance improvements derived primarily from reducing engine stability margins are based upon complex models that are in error by an unknown amount. Additionally, model dependency reduces transportability of mature systems to different applications. These complications, which are intrinsic to the model-based approach, have spurred research in a new direction.

This new approach uses flight measurements and feedback control to provide the adaptive capability. A limited experiment was performed during the PSC program to establish the feasibility of using onboard sensors and step inputs to the cowl, nozzle area, and variable vanes to identify longitudinal force derivatives (ref. 4). These performance derivatives were identified postflight using two methods. The first, a computationally intensive approach, used a maximum likelihood estimator that modeled the longitudinal axis response in three degrees-of-freedom. The second, a simplified approach, contained a least-squares estimator that modeled the longitudinal axis response in one degree-of-freedom. Both methods were successful and proved that measurement-based performance optimization using available sensors is possible and computationally feasible.

Subsequently, a new approach to measurement-based performance optimization evolved from the forcedoscillation technique used to compute dynamic stability derivatives from wind-tunnel test data (ref. 5). This approach identified frequency domain input-output relations using Fourier analyses. Performance gradients are formed using multiterm frequency matching of control and response frequency domain models. An objective function is generated using the performance gradients and formally optimized to produce a coordinated control trim set (ref. 6). This technique, called the Adaptive Aircraft Performance Technology (AdAPT) approach, was evaluated in a high fidelity, nonlinear, six degree-of-freedom simulation of the NASA Advanced Control Technology for Integrated Vehicles (ACTIVE) aircraft (ref. 7). Excellent results from the simulation prompted evaluation of the frequency-based approach using fight test data.
The frequency-based approach has two theoretical advantages. The first is the ability to identify multiple control gradients simultaneously. By targeting distinct excitation frequencies for each control, their corresponding effect on the performance index can be accurately separated. This approach reduces the required excitation period because individual control excitation does not need to be performed in a serial fashion. The approach also enables simultaneous optimization of distinct control effectors. Secondly, the approach exhibits an inherent ability to reject noise. Targeting specific excitation frequencies of known low noise levels minimizes corruption of the gradients. For example, a discrete frequency bin adjacent to the one selected may contain high noise levels caused by structural vibration or atmospheric effects. This noise will not affect identification of the selected frequency bin because the approach uses control and response data only at the selected frequency.

This paper describes results of flight test on the NASA F-15 Highly Integrated Digital Electronic Control (HIDEC) aircraft during the PSC program to validate the described frequency-based system identification approach. Three criteria were investigated to validate the approach across the flight envelope: simultaneous gradient identification, gradient frequency dependency, and repeatability.

\section{Aircraft and Engine Description}

Performance optimization was studied on the NASA F-15 HIDEC research aircraft, a high-performance military fighter aircraft capable of speeds in excess of Mach 2 (fig. 1). Two Pratt \& Whitney (PW) (West Palm Beach, Florida) F100-PW-1128 derivative, afterburning, turbofan engines power the NASA F-15 aircraft. The aircraft has been modified with a digital electronic flight control system (ref. 8).

The F100-PW-1128 engine is a low-bypass ratio, twin-spool, afterburning turbofan technology demonstrator, derived from the F100-PW-100 engine. A full-authority Digital Electronic Engine Control (DEEC) similar to the one for the current production F100-PW220 engine controls the engines. The DEEC software has been modified to accommodate PSC trim commands, but the normal DEEC control loops (i.e., corrected fan speed, $\mathrm{N} 1 \mathrm{C} 2$, and engine pressure ratio (EPR)) were not modified. The DEEC trim commands for subsonic, nonafterburning conditions are perturbations on fan variable vanes, $C I V V$; compressor variable vanes, $R C V V ; \mathrm{N} 1 \mathrm{C} 2$, and nozzle throat area, $A J$. Reference 9 provides a more detailed description of the F100-PW-1128 engine. 


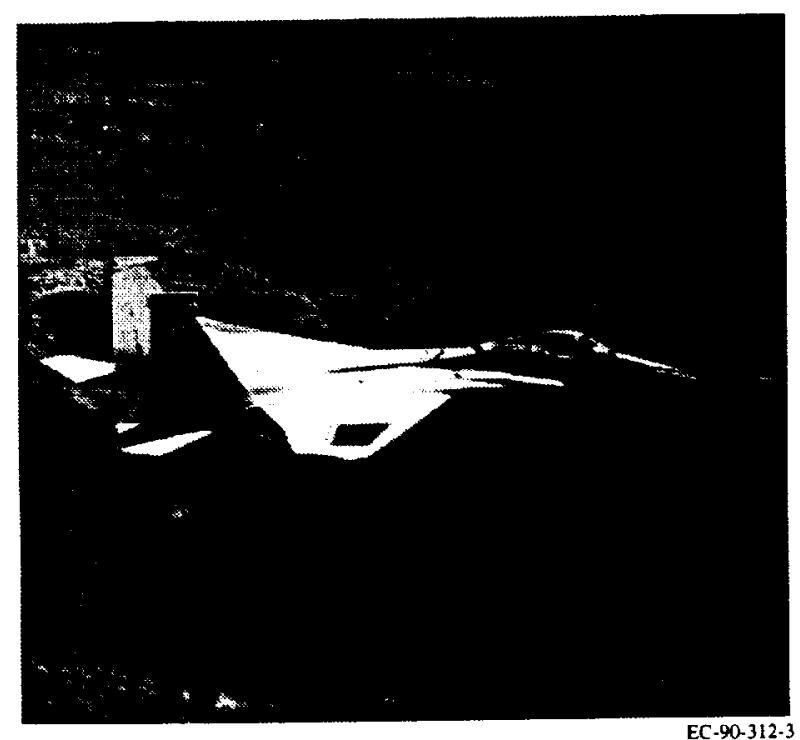

Fig. 1. The NASA F-15 Highly Integrated Digital Electronic Control aircraft.

The NASA F-15 aircraft was also modified with an electronic air inlet controller (EAIC) which allows PSC trim commands to be added to first and third inlet ramp scheduled positions (fig. 2). These inlet ramp schedules were tailored specifically for the F100-PW-1128 engines during supersonic flight to account for the increased engine airflow.
The aircraft was equipped with a NASA flight test instrumentation package which recorded all PSC engine and airframe data as well as the standard set of stability, control, and airdata parameters. These data were recorded at 40 samples/sec for the postflight analysis. Longitudinal acceleration data were gathered from a flight test instrumentation sensor mounted in the noseboom. Engineering units range and resolution of the accelerometer were \pm 1.37 and $0.00268 \mathrm{~g} / \mathrm{bit}$, using the aircraft 10-bit digital-to-analog instrumentation system (ref. 4).

\section{Performance Seeking Control System Description}

The PSC program advances the capability for a fully integrated propulsion flight control system. Whereas previous algorithms provided single variable control for an average engine (ref. 1), the PSC algorithm controlled multiple propulsion system variables while adapting to the measured engine performance. The PSC algorithm optimizes aircraft propulsion system performance during steady-state engine operation. This multimode algorithm minimized fuel consumption at cruise conditions, maximized excess thrust (thrust minus drag) during aircraft accelerations, extended engine life by decreasing fan turbine inlet temperature (FTIT) during cruise or accelerations, and reduced supersonic deceleration time by minimizing excess thrust. Onboard models of the inlet, engine, and nozzle were optimized to compute a set of control trims. Then, these trims were
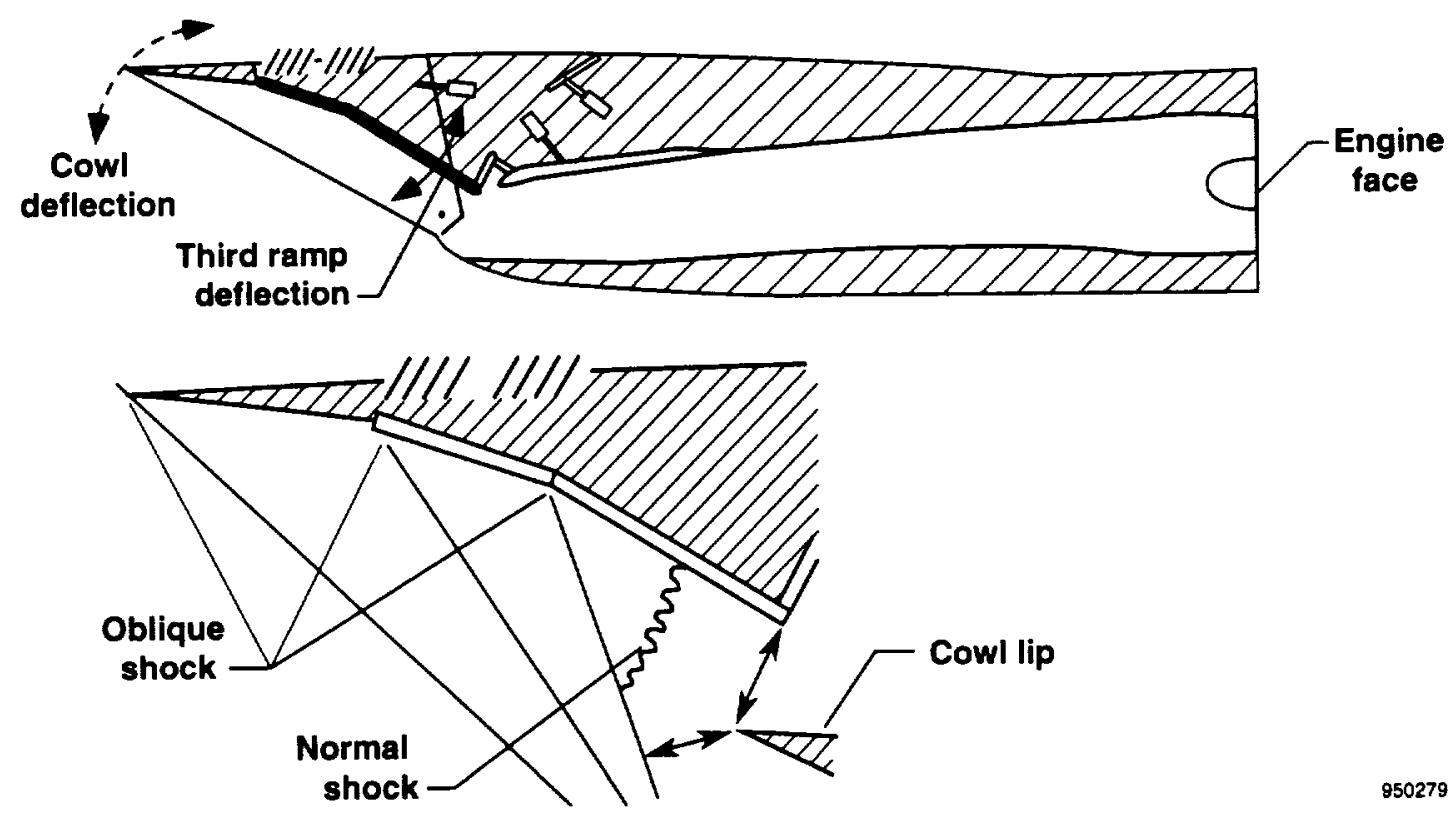

Fig. 2. Side view of the F-15 inlet. 
applied as increments to the nominal engine and inlet control schedules (fig. 3). The onboard engine model was continuously updated to match the operating characteristics of the actual engine cycle through the use of a Kalman filter, which accounts for unmodelled effects. Subsonic and supersonic flight testing was conducted at NASA Dryden covering the four PSC optimization modes and over the full throttle range (ref. 2-3)

To support future work with a frequency-based optimization program, an excitation mode was added to the PSC system. Although the excitation mode was not an original component, it was rapidly prototyped and implemented into the architecture. The implementation of the PSC excitation mode was based on the minimum fuel mode. This approach allowed the algorithm to operate at any power lever angle setting. The PSC trim adder and scale factors zeroed all trim outputs of the optimization and applied sinusoidal trims to the nozzle throat area, inlet first ramp, and cowl (fig. 4). Frequency and amplitude trim characteristics were selected in flight for each control through a variable gain structure. Aircraft control and acceleration data were recorded on the instrumentation system for postflight analysis.

\section{Test Description}

During 5 flights, 31 test maneuvers were flown at 9 conditions ranging from Mach 0.7 and an altitude of $7,000 \mathrm{ft}$ to Mach 2.0 and an altitude of $45,000 \mathrm{ft}$. Table 1 summarizes the conditions for these tests. Mach number and altitude tolerances were \pm 0.01 and $\pm 100 \mathrm{ft}$, respectively. Twenty-six maneuvers were conducted across the envelope to validate the accuracy of the gradient identification during separate and simultaneous control excitations. In addition, five maneuvers were conducted at one condition to quantify the effect of excitation frequency on the identified gradient. To minimize unmodelled effects, the aircraft was stabilized in a hands-off, 1-g, wings-level trim. If possible, autopilot was engaged in the altitude-hold mode. Engine power lever angle was held constant throughout these tests.

Table 1. Test matrix.

\begin{tabular}{cccc}
\hline $\begin{array}{c}\text { Test } \\
\text { condition }\end{array}$ & $\begin{array}{c}\text { Mach } \\
\text { number }\end{array}$ & $\begin{array}{c}\text { Altitude, } \\
\mathrm{ft}\end{array}$ & $\begin{array}{c}\text { Excitation } \\
\text { test }\end{array}$ \\
\hline 1 & 2.00 & 45,000 & AJ/Both \\
2 & 1.60 & 45,000 & AJ/RHO/Both \\
3 & 1.35 & 45,000 & AJ/RHO/Both \\
4 & 0.95 & 45,000 & AJ/RHO/Both \\
5 & 1.40 & 25,000 & AJ/RHO/Both \\
6 & 1.25 & 25,000 & AJ/RHO/Both \\
7 & 0.95 & 25,000 & AJ/RHO/Both/ \\
& & Frequency \\
8 & 0.95 & 10,000 & AJ/RHO/Both \\
9 & 0.70 & 7,000 & AJ/RHO/Both \\
\hline \hline
\end{tabular}

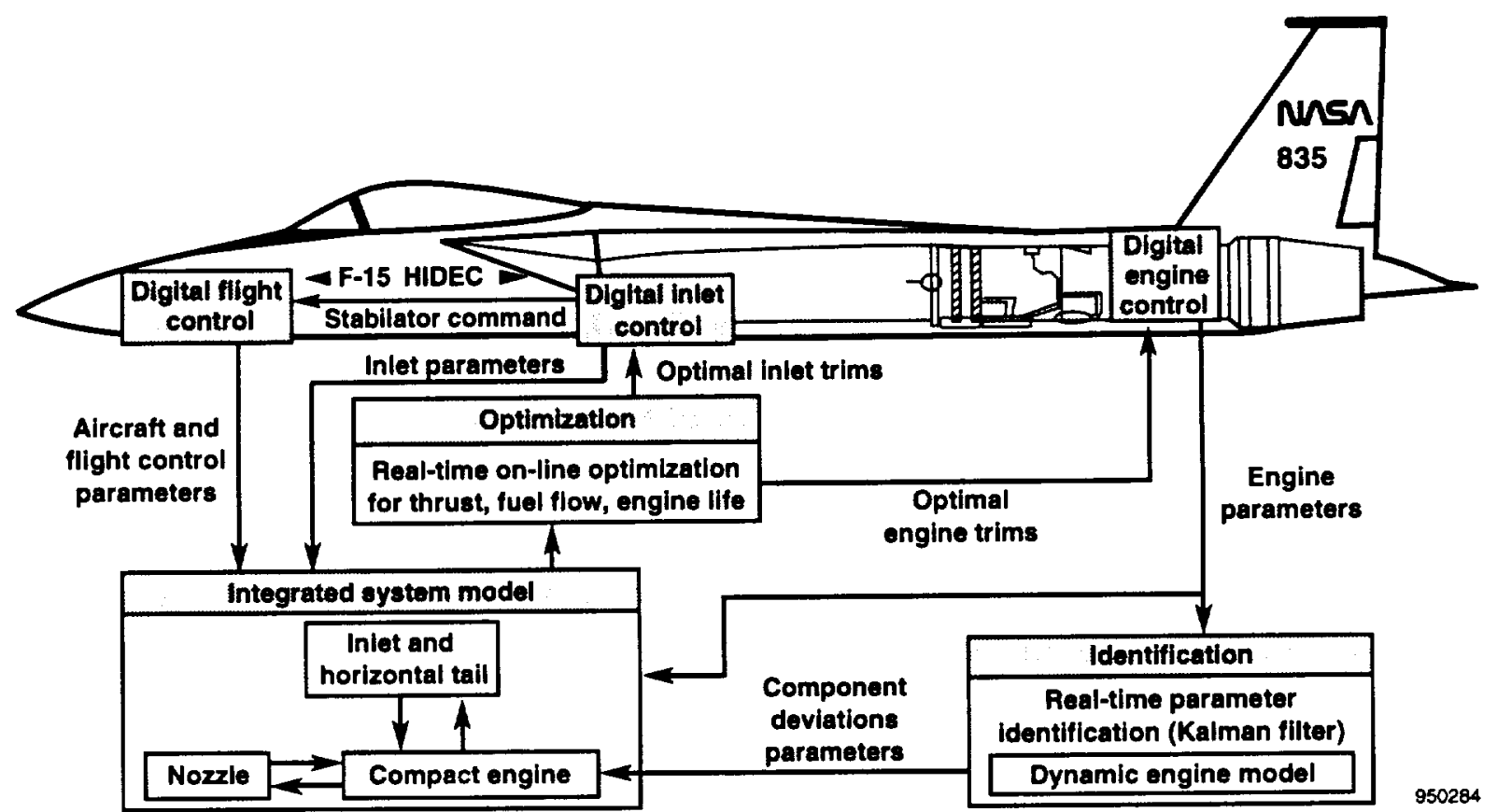

Fig. 3. Performance Seeking Control system. 


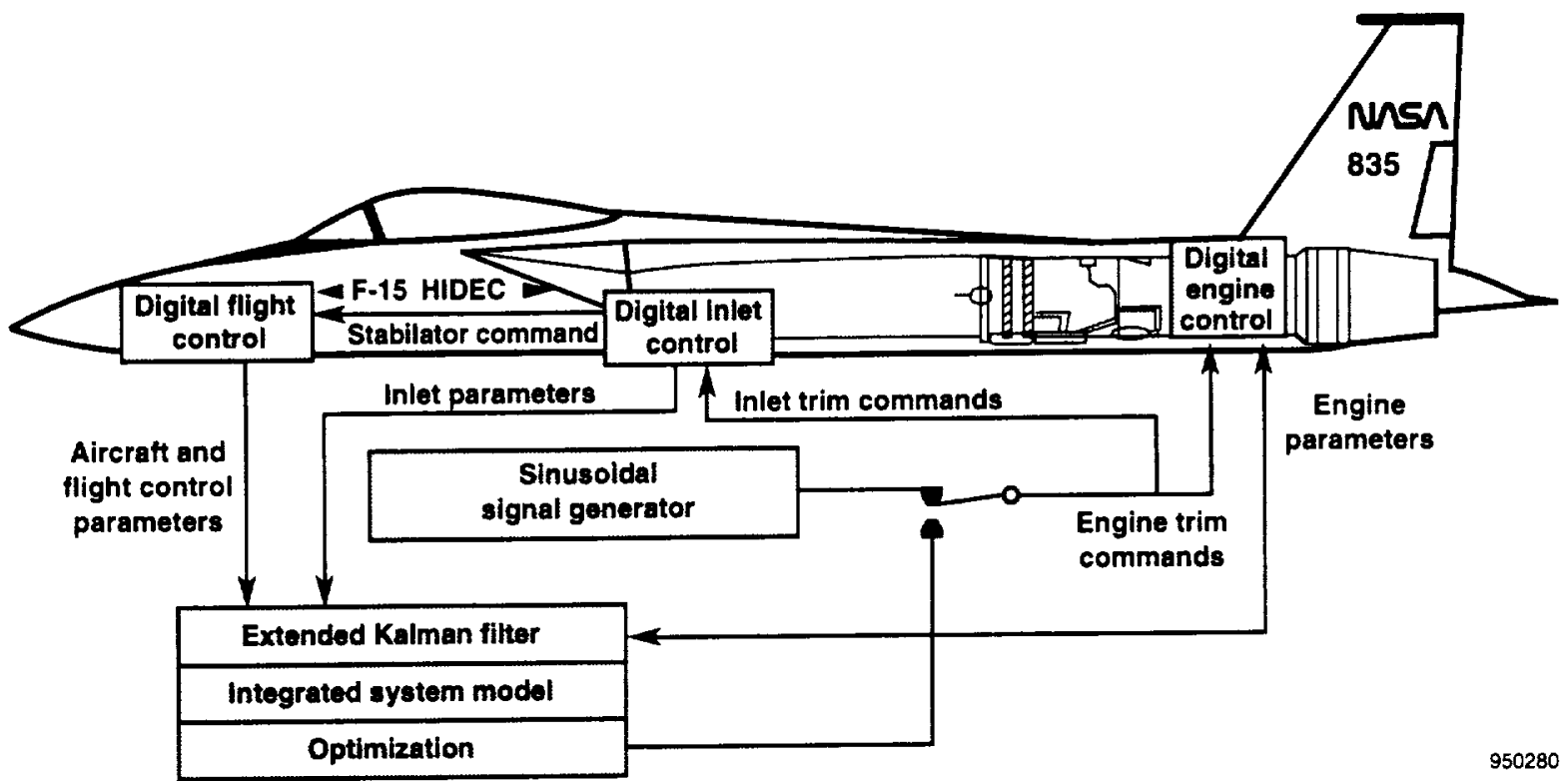

Fig. 4. Performance Seeking Control excitation mode.

\section{Separate versus simultaneous control excitation test}

The separate versus simultaneous control excitation test determined whether simultaneous control excitation degraded the quality of the identified gradients. The performance index for the test was the body-axis longitudinal acceleration, $N_{x}$, measured with the noseboom sensor (ref. 4). Additionally, body-axis normal acceleration, $N_{z}$, was measured to evaluate orthogonal axis activity during excitation.

Two controls were selected for this test. The first, an aircraft control, was the inlet first ramp or cowl position, $R H O$, and nozzle throat area. The cowl was selected because of the integrated nature of the effector. The variable geometry inlet is an external compression design. First and third ramp positions were scheduled with Mach number, total temperature, and angle of attack to efficiently channel engine airflow and maximize pressure recovery. The first ramp has a large two-dimensional flat plate configuration and is exposed to relatively undisturbed flow at the forward fuselage. This configuration produces significant aerodynamic forces and moments at subsonic and supersonic conditions. The inlet first ramp primarily affects pressure recovery at the engine face and, in turn, net thrust. In addition to having a thrust effect, the inlet first ramp position also affects the aircraft aerodynamics, and its effect can be traded with the stabilator's to reduce trim drag while maintaining condition. The second control effector chosen for the test was an engine control, nozzle throat area. Nozzle throat area was chosen because it has a significant effect on thrust subsonically and supersonically.

A maneuver block at a specific flight condition consisted of an $A J$ excitation, followed by a $R H O$ excitation, and ended with a simultaneous excitation of the two controls. Once the pilot stabilized the aircraft on condition, stabilized data were gathered for $30 \mathrm{sec}$ for SNR calculations after which the pilot initiated the control excitation. Each control excitation lasted approximately $30 \mathrm{sec}$ to $1 \mathrm{~min}$. Between each excitation maneuver, stabilized data were gathered so that noise information could be quantified. By performing the three maneuvers in succession, variations in trim, atmosphere, and weight were reduced.

\section{Frequency parametric test}

The frequency parametric test established whether a frequency dependency existed in the identified gradients. Ideally, gradients remain independent of the excitation frequency across the entire bandwidth of the control. In reality, the response is corrupted by actuator rate limiting, structural coupling, aeroservoelastic, or control surface damping effects as the control excitation frequency increases. Consequently, the objective of the test was to quantify the frequency range within the bandwidth of the control that is independent of frequency. 
Mach 0.95 at an altitude of $25,000 \mathrm{ft}$ was the flight condition selected for the test. The performance index and the control effector were $N_{x}$ and $A J$, respectively. Table 2 summarizes the frequency range tested. The convergent actuator that controls the nozzle area is pneumatically driven and exhibits a relatively low bandwidth. As such, an appropriate frequency range between 0.02 and $0.20 \mathrm{~Hz}$ was selected. The commanded trim amplitude for the five maneuvers was $0.30 \mathrm{ft}^{2}$. This test procedure was similar to that of the separate versus simultaneous control excitation test except all five maneuvers were performed in succession.

Table 2. Frequency parametric test matrix.

\begin{tabular}{cccc}
\hline $\begin{array}{c}\text { Test } \\
\text { point }\end{array}$ & $\begin{array}{c}\text { Mach } \\
\text { number }\end{array}$ & $\begin{array}{c}\text { Altitude, } \\
\mathrm{ft}\end{array}$ & $\begin{array}{c}\text { Excitation } \\
\text { frequency, Hz }\end{array}$ \\
\hline 1 & 0.95 & 25,000 & 0.020 \\
2 & 0.95 & 25,000 & 0.049 \\
3 & 0.95 & 25,000 & 0.098 \\
4 & 0.95 & 25,000 & 0.156 \\
5 & 0.95 & 25,000 & 0.195 \\
\hline
\end{tabular}

\section{Repeatability test}

The repeatability test established the sensitivity of the identified gradients to random effects, such as noise and data windowing. For the identification approach to be satisfactory, only small variations in the results were expected for data gathered over the same maneuver. No additional maneuvers were required to perform this test. The analysis was performed on the same data as that of the separate versus simultaneous control excitation test. The window length selected for the analysis was $25.6 \mathrm{sec}$. Approximately $2 \mathrm{~min}$ of excitation data were collected during each maneuver. By successively offsetting the starting point of the analysis window $12.5 \mathrm{sec}, 6$ or 7 sets of analysis could be performed on each maneuver. This technique was used to evaluate the repeatability of the identification approach because it minimized changes in unmodelled effects.

\section{Analysis and Results}

The frequency-based system identification method was validated by investigating simultaneous control excitation, frequency dependency, and repeatability across the flight envelope of the F-15 HIDEC aircraft. Results of each test are presented separately.

\section{Separate versus simultaneous control excitation test}

A series of steady-state cruise tests was conducted at nine flight conditions throughout the aircraft envelope. Figures 5 and 6 present a typical simultaneous maneuver performed at Mach 2.0 and an altitude of 45,000 ft. The number of data points analyzed in the discrete Fourier transform points, DFTP, was $2^{10}$ or 1024 samples with a data rate, $S R$, of 40 samples/sec, translating into 25.6 $\mathrm{sec}$. To enhance the likelihood of gradient identification using frequency separation, carefully chosen excitation frequencies, $\omega_{i}$, were calculated using equation 1 .

$$
\omega_{i}=(\operatorname{SNR} / D F T P)^{*} n_{i}
$$

The excitation frequencies were applied to $A J$ and $R H O$ at frequency bin numbers $\mathrm{n}_{n}=2\left(\omega_{n}=0.078 \mathrm{~Hz}\right)$, and $n_{c}=7\left(\omega_{c}=0.273 \mathrm{~Hz}\right)$. This selection reduces the interaction of the controls and their higher order effects. The $A J$ and $R H O$ excitation trim amplitudes were \pm 0.14 $\mathrm{ft}^{2}$ (3.9 percent control full-scale range F.S.) and $\pm 0.68^{\circ}$ ( 4.5 percent F.S.), respectively, to determine the linear characteristics, reducing the effects of amplitude.

Figure 5 contains time histories of $N_{x}$ and $N_{z}$ measured during the excitation period. At this flight condition, both time histories show that the aircraft response is dominated by the effect of the cowl. With $N_{z}$ amplitudes averaging $0.064 \mathrm{~g}$, the excitation was noticeable to the pilot, but they were not objectionable.

Figure 6 shows the normalized spectrum, $P n$, of the controls and response before and during the excitation period. The normalized spectrum is a useful calculation because a unit sinusoid in the time domain corresponds to unit amplitude in the frequency domain.

$$
P n(\mathrm{x})=2 * \mathrm{abs}(\mathrm{FFT}(\mathrm{x})) / \mathrm{DFTP}
$$

The steady-state data gathered just before the excitation period were used to assess the noise level at the excitation frequencies. Because the gradient identification approach uses frequency separation to discriminate noise from actual response to the control, it is critical to choose an excitation frequency that contains low noise levels.

Figure 6 also shows $A J$ and $R H O$ excitation trim amplitudes in square feet and degrees as a function of frequency in hertz. Frequency bin $2, \mathrm{n}_{n}=2\left(\omega_{n}=\right.$ $0.078 \mathrm{~Hz}$ ), shows that $A J$ excitation generated an average perturbation amplitude of $0.14 \mathrm{ft}^{2}$ during the data collection period. Frequency bin $7, \mathrm{n}_{c}=7\left(\omega_{c}=\right.$ $0.273 \mathrm{~Hz}$ ), shows that $R H O$ excitation produced an 

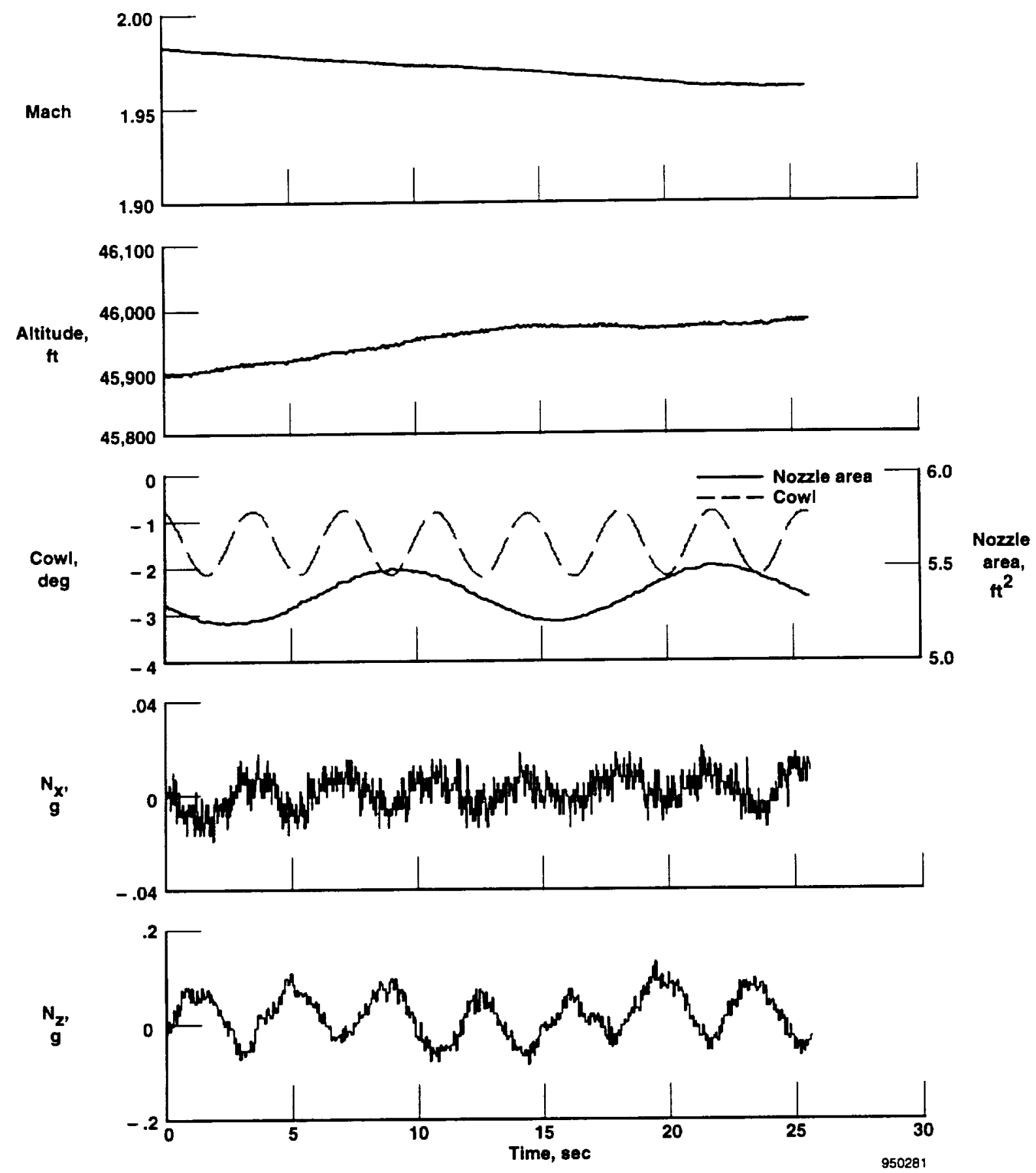

Fig. 5. Time histories of simultaneous nozzle area and cowl excitation. 

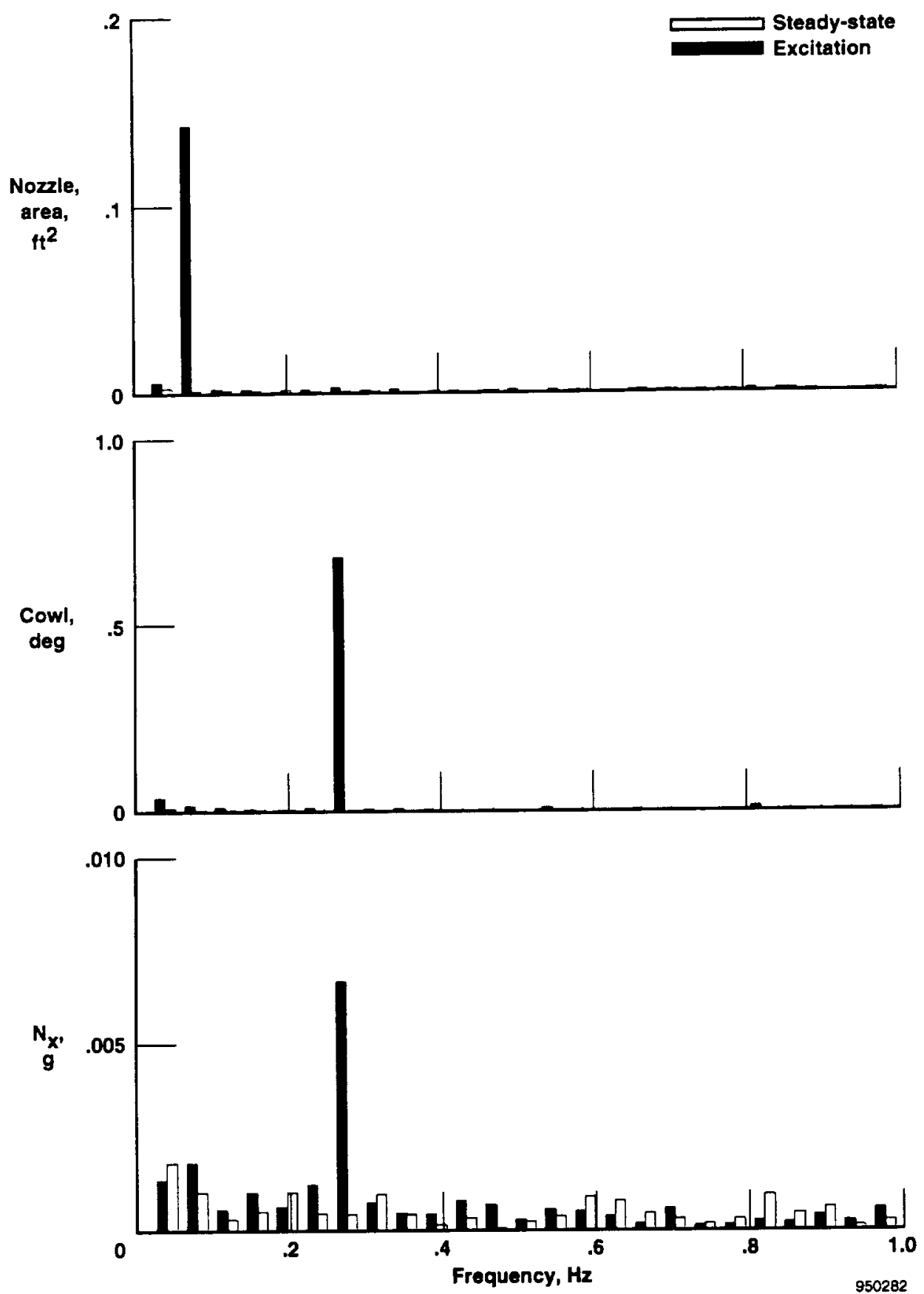

Fig. 6. Normalized spectrum of simultaneous nozzle and cowl excitation. 
average perturbation amplitude of $0.68^{\circ}$. Figure 6 presents the normalized spectrum of $N_{x}$. This graph illustrates the greater effectiveness of $R H O$ over $A J$ during this maneuver. The cowl produced $6.7 \mathrm{mg}$ of $N_{x}$, while the nozzle only managed $1.8 \mathrm{mg}$ of $N_{x}$.

At Mach numbers greater than 1.4, shock position is critical for performance. Small changes in location of the first oblique shock significantly affect spillage drag and pressure recovery. Additionally, cowl pitching moment effectiveness becomes significant when compared to the stabilator. Large trim drag reductions are possible by offsetting stabilator trim position. Nozzle area becomes less effective as Mach number increases because engine pressure ratio has less affect on thrust than airflow. Noise levels in bins 2 and 7 were below $1 \mathrm{mg}$. The nondimensional derivative, $C_{x_{\delta_{u}}}$ longitudinal force effectiveness, was calculated using the following equation at the excitation frequency of each control:

$$
C_{x_{\delta_{u}}}=\operatorname{abs}\left(\operatorname{FFT}\left(N_{x}\right) / \operatorname{FFT}(\mathrm{u})\right)^{*} \mathrm{~F} . S .(\mathrm{u}) * W t / \bar{q} / S
$$

where

$$
\begin{aligned}
& u=\text { control effector, } A J \text { or } R H O \\
& \text { F.S.(u) = full-scale control deflection-3.65 } \mathrm{ft}^{2} \\
& \text { for nozzle area, } 15^{\circ} \text { for cowl } \\
& W t \quad=\quad \text { average weight over the maneuver, } \mathrm{lb} \\
& \bar{q}=\text { average dynamic pressure over the } \\
& \text { maneuver, pfs } \\
& S=\text { reference wing area, } \mathrm{ft}^{2}
\end{aligned}
$$

Figure 7 shows summary plots of separate and simultaneous identification of nozzle area and cowl longitudinal force effectiveness as a function of Mach number for altitudes of 10,000, 25,000, and 45,000 ft. Overall, excellent agreement was exhibited between the separate and simultaneous identification tests at all flight conditions. Small differences in the two techniques result, in part, from interactions between the controls during simultaneous excitation and unmodelled effects, such as differences in trim flight and atmospheric conditions. Additionally, the analysis revealed the relative effectiveness between the cowl and nozzle area to be somewhat unexpected. As expected at low Mach numbers, nozzle area effectiveness was high, and the cowl was practically ineffective. As Mach number increased, the cowl rapidly became increasingly effective as the nozzle area effectiveness quickly decreased. At an altitude of $45,000 \mathrm{ft}$, cowl effectiveness surpassed the nozzle at Mach 1.6. At Mach 2.0, cowl effectiveness approached the highest levels attained by the nozzle at low Mach numbers. This reversal in effectiveness supports incorporating a variable geometry inlet into an F-15 aircraft. Increased performance offsets the associated penalties of increased complexity and added weight. At lower altitudes, the trend indicates that this reversal occurs at lower Mach numbers. Such reversals are probably caused by increased dynamic pressure.

To gauge the fidelity of the identified gradients, SNR calculations were performed for all maneuvers. The SNR was calculated from the steady-state and excitation portions of the maneuver at the excitation frequency for each control, allowing a direct assessment of the confidence of the identification. The inherent assumption to this approach was that noise characteristics just before the excitation were representative of the noise during the excitation. Because the steady-state noise data were gathered within $60 \mathrm{sec}$ of the excitation data during the same maneuver, the noise characteristics did not change significantly during this period. As a result, the approach was deemed satisfactory for quantifying the steady-state noise levels. The steady-state trim data before the excitation provided base noise levels at the excitation frequency. This quantity was subtracted from the measured $N_{x}$ level during the excitation to calculate the actual response level. Equation 4 shows the calculation.

$$
\mathrm{SNR}=\mathrm{abs}\left(\frac{P n\left(N_{x}\right) \mathrm{n}_{\mathrm{i}}-P n\left(N_{x}\right)_{\mathrm{n}_{\mathrm{i}}^{\prime}}}{\operatorname{Pn}\left(N_{x}\right)_{\mathrm{n}_{\mathrm{i}}^{\prime}}}\right)
$$

where

$$
\begin{aligned}
& \mathrm{n}_{\mathrm{i}} \quad=\text { frequency bin } \mathrm{i} \text { during excitation } \\
& \mathrm{n}_{\mathrm{i}}^{\prime} \quad=\text { frequency bin } \mathrm{i} \text { during steady state }
\end{aligned}
$$

Figures $8(\mathrm{a})-8(\mathrm{c})$ present summary plots of SNR for separate and simultaneous identification of nozzle area and cowl longitudinal force effectiveness as a function of Mach number for altitudes of 10,000, 25,000, and $45,000 \mathrm{ft}$. The $\mathrm{SNR}$ calculation provides an effective means of assessing the confidence of the identification. These ratios were consistently high for nozzle area and cowl in regions of the envelope where the respective control was most effective. Signal-to-noise ratios above 2 indicated good confidence in the identification. 


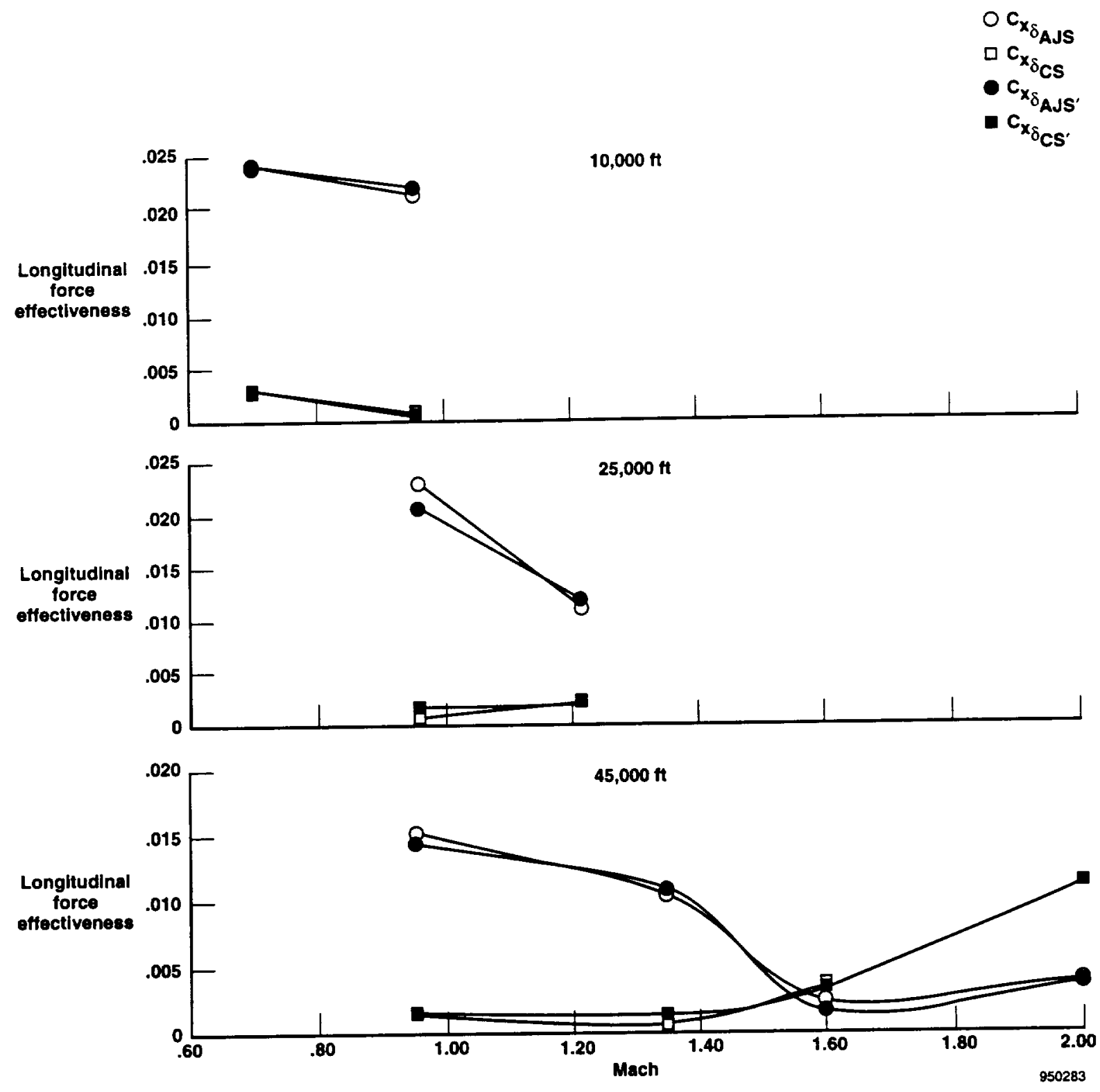

Fig. 7. Comparison of separate and simultaneous identification of nozzle area and cowl longitudinal effectiveness as a function of Mach number at varying altitudes. 


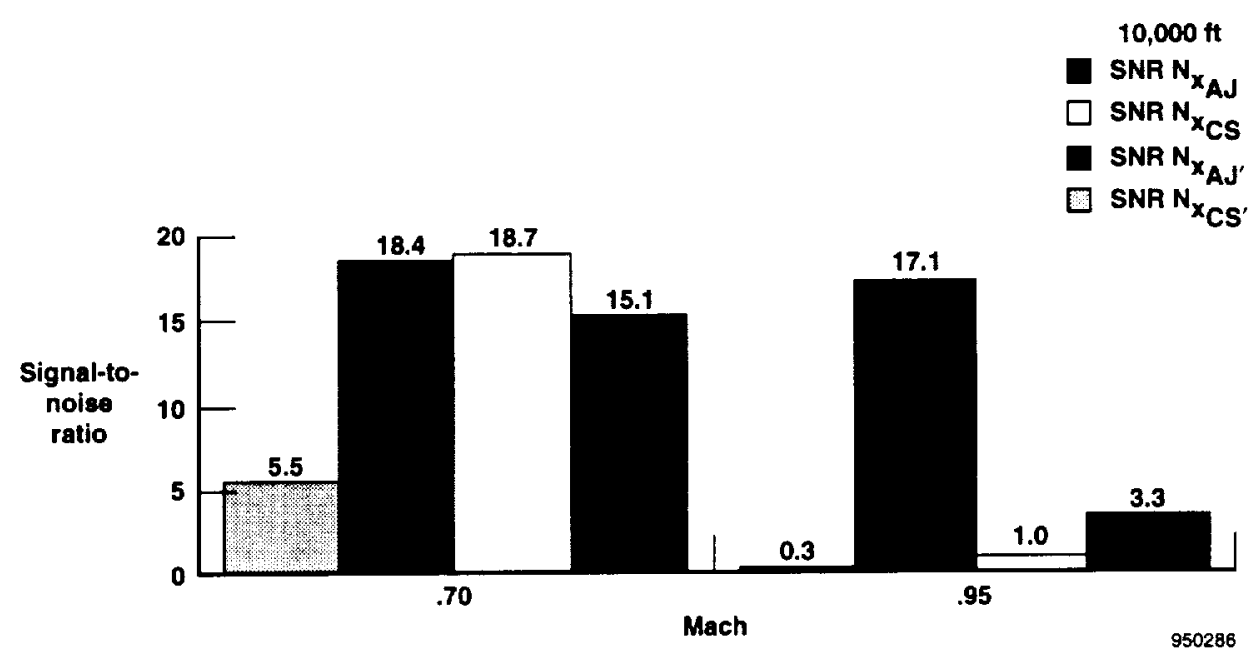

(a) $10,000 \mathrm{ft}$

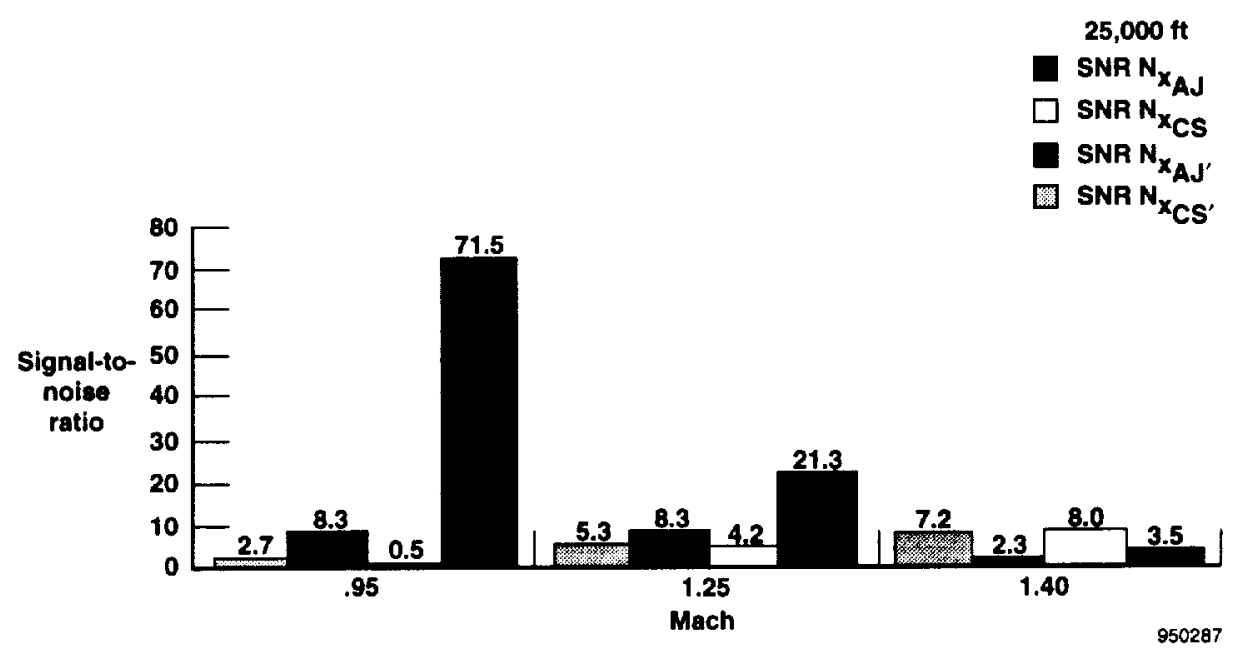

(b) $25,000 \mathrm{ft}$

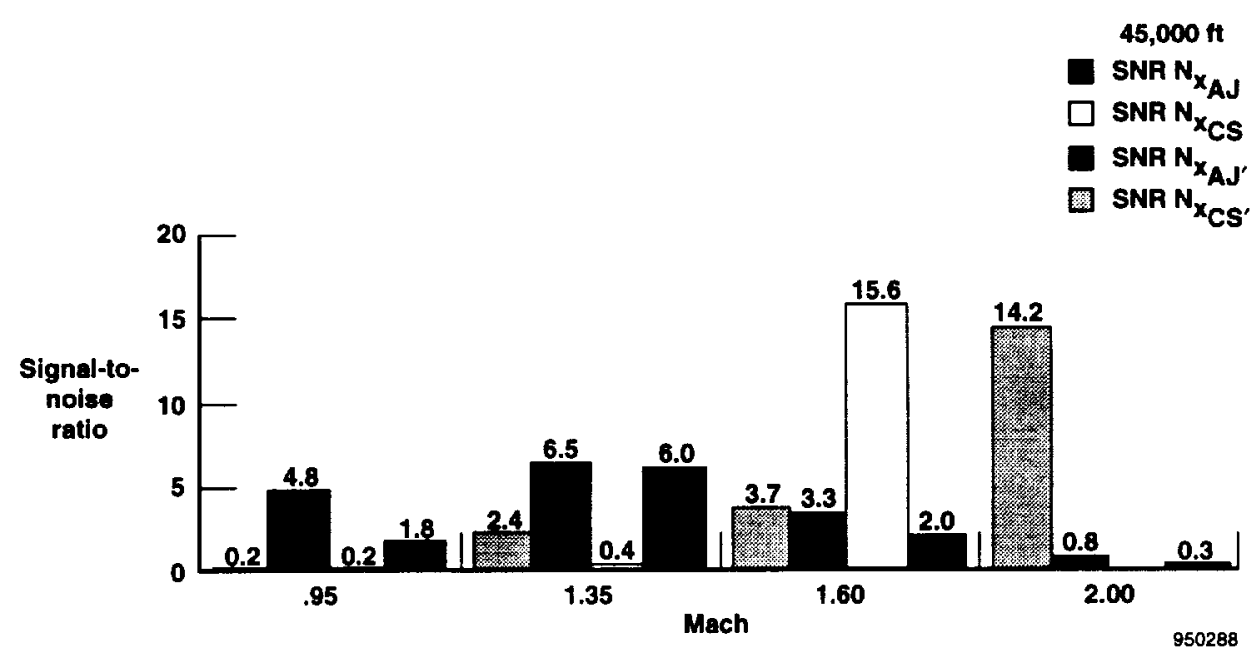

(c) $45,000 \mathrm{ft}$

Fig. 8. Comparison of separate and simultaneous excitation signal-to-noise ratio as a function of Mach number at varying altitudes. 
Signal-to-noise ratios equal to and below 1 indicated response levels were within the threshold of the noise, and little confidence existed in the results. Typically, this threshold occurred at effectiveness values below 0.0025 . In general, SNR were consistent between the simultaneous and separate excitation tests. Simultaneous and separate excitation results were consistent above 2 or below 1 . Although there were exceptions, these were predominantly caused by a change in noise level between the two tests and not by a significant change in signal level.

For example at an altitude of $25,000 \mathrm{ft}$ and at Mach 0.95, SNR for nozzle area were 8.3 and 71.5 for the simultaneous and separate excitation tests (fig. 8(b)). Noise levels changed by a factor of 4 at the excitation frequency between the two tests. During the separate excitation test, $N_{x}$ noise levels were $0.23 \mathrm{mg}$, a relatively low level. Subsequently, during the simultaneous excitation test, $N_{x}$ noise levels averaged $0.94 \mathrm{mg}$, a more representative value. This increase directly results in a fourfold change in the SNR. Additionally, during the simultaneous excitation test, the excitation amplitude was reduced inadvertently from 0.3 to $0.2 \mathrm{ft}^{2}$. This reduction lowered the signal level during the simultaneous test, precluding meaningful comparison of the two SNR.

\section{Frequency parametric test}

Figures 9 (a) and 9(b) present nozzle area longitudinal effectiveness and nozzle area trim amplitude as a function of frequency at a flight condition of Mach 0.95 and an altitude of $25,000 \mathrm{ft}$. Nozzle area longitudinal effectiveness remained relatively constant below $0.049 \mathrm{~Hz}$. Above $0.049 \mathrm{~Hz}$, rate limiting of the nozzle area actuators was encountered (fig. 9(a)). The commanded nozzle area trim amplitude was held constant at $0.30 \mathrm{ft}^{2}$. Figure $9(\mathrm{~b})$ shows the nozzle area feedback trim amplitude attenuating as frequency increases above $0.049 \mathrm{~Hz}$. By $0.2 \mathrm{~Hz}$, the amplitude had attenuated by 65 percent. The nonlinearities introduced by the rate limiting spread the excitation energy across several frequency bins, reducing the apparent effectiveness at the fundamental frequency. This effect precluded identifying a bandwidth greater than $0.049 \mathrm{~Hz}$. If the excitation amplitude had been 0.10 instead of $0.30 \mathrm{ft}^{2}$, a greater bandwidth may have been identified. Although a limited number of frequency test points were obtained, results of the frequency parametric test of the nozzle area indicate that an adequate frequency band exists wherein gradient values are independent of excitation frequency.

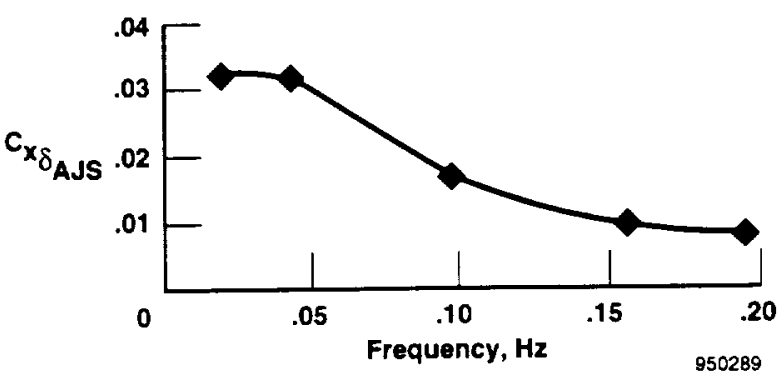

(a) Nozzle throat area longitudinal force effectiveness as a function of frequency at Mach 0.95 and an altitude of $25,000 \mathrm{ft}$.

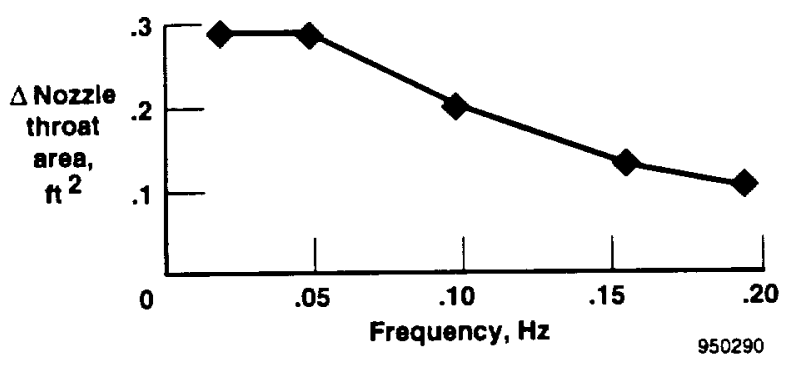

(b) Trim nozzle throat area amplitude as a function of frequency at Mach 0.95 and an altitude of $25,000 \mathrm{ft}$.

Fig. 9. Frequency parametric test results.

\section{Repeatability test}

Repeatability analysis was performed at two flight conditions using data from the simultaneous excitation test. The flight conditions chosen for the analysis represent conditions where effectiveness was greatest for each control. Results of the repeatability test showed that variation in identified gradients was small in both cases tested.

Figure 10(a) presents nozzle area longitudinal effectiveness as a function of analysis window start time for a maneuver performed at a flight condition of Mach 0.70 and an altitude of $7000 \mathrm{ft}$. Seven sets of analysis were performed over $100 \mathrm{sec}$. The solid horizontal line indicates the mean value, and the dotted lines indicate the 95 percent confidence bounds on the mean value (ref. 10). Results show a 95 percent probability that the mean $A J$ longitudinal force effectiveness equals $0.023 \pm 8.3$ percent.

Figure 10(b) presents cowl longitudinal effectiveness as a function of analysis window start time for a maneuver performed at a flight condition of Mach 2.0 and an altitude of $45,000 \mathrm{ft}$. Six sets of analysis were 


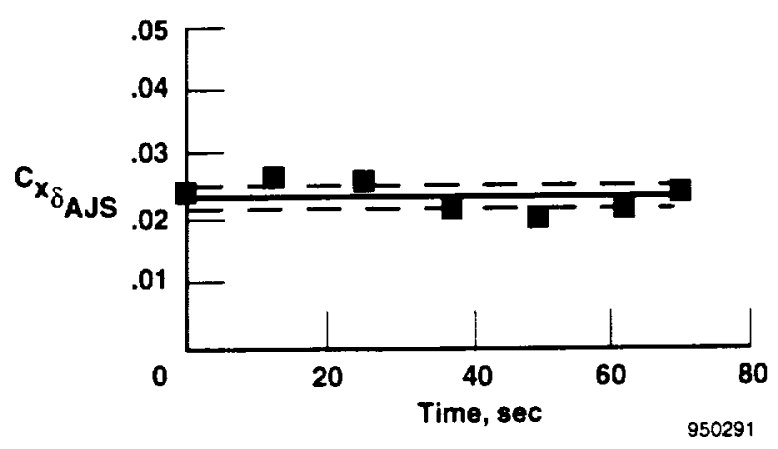

(a) Nozzle throat area longitudinal force effectiveness as a function of data window start time at Mach 0.70 and an altitude of $7000 \mathrm{ft}$.

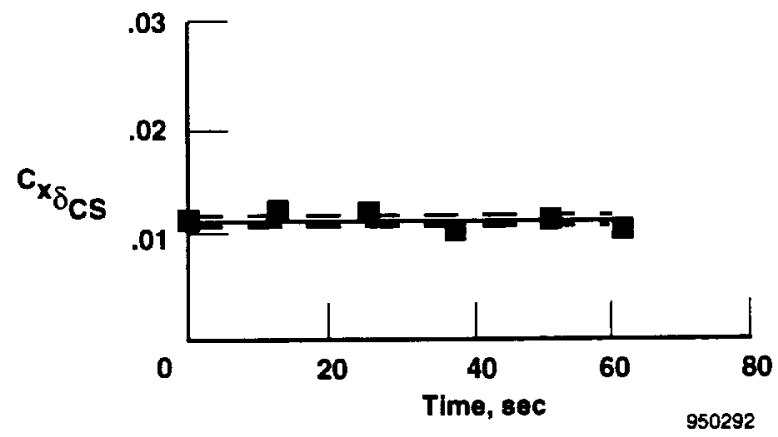

(b) Cowl longitudinal force effectiveness as a function of data window start time at Mach 2.0 and an altitude of $45,000 \mathrm{ft}$.

Fig. 10. Nozzle throat area and cowl repeatability test results.

performed over $90 \mathrm{sec}$. Results show a 95 percent probability that the mean cowl longitudinal force effectiveness equals $0.0113 \pm 4.3$ percent. With mean confidence bounds less than 10 percent for the nozzle area and cowl, the repeatability demonstrated the identification approach to be satisfactorily robust to unmodelled effects.

\section{Concluding Remarks}

A frequency-based system identification approach was fight tested on the NASA F-15 Highly Integrated Digital Electronic Control aircraft during the Performance Seeking Control program. Results demonstrated that performance gradients identified simultaneously compare well with those identified separately. Signal-to-noise ratio calculations provided a means to judge relative significance of identified values and discrepancies. Secondly, although limited data were gathered, a frequency band was identified within which gradient values are independent of excitation frequency. Additionally, repeatability analysis produced consistent results and showed the identification approach to be robust to noise and data windowing. These results indicate that this approach to measurement-based performance system identification possesses inherent strengths that make it an excellent candidate for a realtime onboard implementation in the future.

Limited flight data were gathered for the frequency dependency test. All data were gathered at a single flight condition using only one control effector. In future experiments, additional engine and airframe controls will be used throughout the envelope to quantify the effects of frequency on gradients. For this investigation, two controls were used to substantiate the simultaneous identification capability. In follow-on research, up to eight effectors will be controlled simultaneously to test the algorithm. With the success of this experiment, a real-time implementation of this method will be flight tested on an airframe and propulsion integration testbed called the Advanced Control Technology for Integrated Vehicles. The capabilities of the aircraft and its systems will greatly facilitate integrated controls research in the future.

\section{References}

1. Highly Integrated Digital Electronic Control Symposium, NASA CP-3024, 1989.

2. Gilyard, Glenn B. and John S. Orme, Subsonic Flight Test Evaluation of a Performance Seeking Control Algorithm on an F-15 Airplane, NASA TM4400, 1992.

3. Orme, John S. and Timothy R. Conners, Supersonic Flight Test Results of a Performance Seeking Control Algorithm on a NASA F-15 Aircrafi, AIAA 94-3210, June 1994.

4. Schkolnik, Gerard S., Identification of Integrated Airframe-Propulsion Effects on an F-15 Aircraft for Application to Drag Minimization, NASA TM-4532, 1993.

5. Chambers, Joseph R. and Sue B. Grafton, Static and Dynamic Longitudinal Stability Derivatives of a Powered 1/9-Scale Model of a Tilt-Wing V/STOL Transport, NASA TN D-3591, 1966.

6. Hreha, M., G. Schkolnik, and J. Orme, An Approach to Aircraft Performance Optimization Using Thrust Vectoring, AIAA 94-3361, June 1994. 
7. Doane, P., R. Bursey, and G. Schkolnik, F-15 ACTIVE: A Flexible Propulsion Integration Testbed, AIAA 94-3360, June 1994.

8. Burcham, Frank W., Jr., Lawrence P. Meyers, and Kevin R. Walsh, Flight Evaluation Results for a Digital Electronic Engine Control in a F-15 Airplane, NASA TM-84918, 1983.
9. Meyers, Lawrence P. and Frank W. Burcham, Jr., Preliminary Flight Test Results of the F100 EMD Engine in a F-15 Airplane, NASA TM-85902, 1984.

10. Coleman, Hugh W. and W. Glenn Steele, Jr., Experimentation and Uncertainty Analysis for Engineers, Wiley \& Sons, New York, 1989. 
Public reporting burden tor this collection of information is estimated to average 1 hour per response, including ine time lor reviewing instructions. searching existing data sources. gathering and maintaining the data needed, and completing and reviewing the collection of inlormation. Send comments regarding this burden estimate or any other aspect of this coliection of information. Including suggestions tor reducing this burden. To Washington Headquarters Services. Directorale lor Inlomalion Davis Highway. Suite 1204. Artingion. VA 22202-4302, and to the Office of Managerment and Budget, Paperwork Reduction Propect (0704-0188), Washington, DC 20503.

1. AGENCY USE ONLY (Leave blank)

\section{REPORT DATE}

July 1995
3. REPORT TYPE AND DATES COVERED

Technical Memorandum

4. TITLE AND SUBTITLE 5. FUNDING NUMBERS

Flight Test Validation of a Frequency-Based System Identification Method on an F-15 Aircraft

6. AUTHOR(S)

WU 505-68

Gerard S. Schkolnik, John S. Orme and Mark A. Hreha

7. PERFORMING ORGANIZATION NAME(S) AND ADDRESS(ES)

8. PERFORMING ORGANIZATION REPORT NUMBER

NASA Dryden Flight Research Center

P.O. Box 273

H-2059

Edwards, California 93523-0273

10. SPONSORING/MONITORING

AGENCY REPORT NUMBER

National Aeronautics and Space Administration

Washington, DC 20546-0001

NASA TM-4704

11. SUPPLEMENTARY NOTES

Presented as AIAA 95-2362 at the 31st AIAA/ASME/SAE/ASEE Joint Propulsion Conference and Exhibit, San Diego, California, July 10-12, 1995. (Mark A. Hreha is employed by McDonnell Douglas Aerospace, St. Louis, Missouri.)

12a. DISTRIBUTIONAVAILABILITY STATEMENT

12b. DISTRIBUTION CODE

Unclassified-Unlimited

Subject Category 08

13. ABSTRACT (Maximum 200 worda)

A frequency-based performance identification approach was evaluated using flight data from the NASA F-15 Highly Integrated Digital Electronic Control aircraft. The approach used frequency separation to identify the effectiveness of multiple controls simultaneously as an alternative to independent control identification methods. Fourier transformations converted measured control and response data into frequency domain representations. Performance gradients were formed using multiterm frequency matching of control and response frequency domain models. An objective function was generated using these performance gradients. This function was formally optimized to produce a coordinated control trim set. This algorithm was applied to longitudinal acceleration and evaluated using two control effectors: nozzle throat area and inlet first ramp. Three criteria were investigated to validate the approach: simultaneous gradient identification, gradient frequency dependency, and repeatability. This report describes the flight test results. These data demonstrate that the approach can accurately identify performance gradients during simultaneous control excitation independent of excitation frequency.

\begin{tabular}{|c|c|c|c|}
\hline \multirow{2}{*}{\multicolumn{3}{|c|}{$\begin{array}{l}\text { 14. SUBJECT TERMS } \\
\text { Adaptive control, Aircraft flight tests, Aircraft performance, Performance } \\
\text { optimization, Control effectiveness }\end{array}$}} & \multirow{2}{*}{$\begin{array}{l}\text { 15. NUMBER OF PAGES } \\
19 \\
\text { 16. PAICE CODE } \\
\text { AO3 }\end{array}$} \\
\hline & & & \\
\hline $\begin{array}{l}\text { 17. SECUATYY CLASSIFICATION } \\
\text { OF REPORT }\end{array}$ & $\begin{array}{l}\text { 18. SECUATY CLASSIFICATION } \\
\text { OF THIS PAGE }\end{array}$ & $\begin{array}{l}\text { 19. SECUATTY CLASSIFICATION } \\
\text { OF ABSTRACT }\end{array}$ & 20. LIMITATION OF ABSTRACT \\
\hline Unclassified & Unclassified & Unclassified & Unlimited \\
\hline
\end{tabular}

